\title{
Two-warehouse inventory model for deteriorating items with price-sensitive demand and partially backlogged shortages under inflationary conditions
}

\author{
Chandra K. Jaggi $^{\mathrm{a}^{*}}$, Sarla Pareek ${ }^{\mathrm{b}}$, Aditi Khanna ${ }^{\mathrm{a}}$ and Ritu Sharma ${ }^{\mathrm{b}}$
}

\begin{tabular}{l}
${ }^{a}$ Department of Operational Research, Faculty of Mathematical Sciences, University of Delhi, Delhi 110007, India \\
${ }^{b}$ Centre for Mathematical Sciences, Banasthali University, Banasthali-304022, Rajasthan, India \\
\hline C H R O N I C L E
\end{tabular}

Article history:

Received July 62014

Received in Revised Format

August 52014

Accepted August 282014

Available online

September 42014

Keywords:

Two-warehouse

Price-dependent demand

Deterioration

Partial Backlogging

Inflation

FIFO/LIFO

\begin{abstract}
In today's competition inherited business world, managing inventory of goods is a major challenge in all the sectors of economy. The demand of an item plays a significant role while managing the stock of goods, as it may depend on several factors viz., inflation, selling price, advertisement, etc. Among these, selling price of an item is a decisive factor for the organization; because in this competitive world of business one is constantly on the lookout for the ways to beat the competition. It is a well-known accepted fact that keeping a reasonable price helps in attracting more customers, which in turn increases the aggregate demand. Thus in order to improve efficiency of business performance organization needs to stock a higher inventory, which needs an additional storage space. Moreover, in today's unstable global economy there is consequent decline in the real value of money, because the general level of prices of goods and services is rising (i.e., inflation). And since inventories represent a considerable investment for every organization, it is inevitable to consider the effects of inflation and time value of money while determining the optimal inventory policy. With this motivation, this paper is aimed at developing a two-warehouse inventory model for deteriorating items where the demand rate is a decreasing function of the selling price under inflationary conditions. In addition, shortages are allowed and partially backlogged, and the backlogging rate has been considered as an exponentially decreasing function of the waiting time. The model jointly optimizes the initial inventory and the price for the product, so as to maximize the total average profit. Finally, the model is analysed and validated with the help of numerical examples, and a comprehensive sensitivity analysis has been performed which provides some important managerial implications.
\end{abstract}

\section{Introduction}

Demand and price are perhaps some of the most fundamental concepts of inventory management and they are also the backbone of a market economy. The law of demand states that, if all other factors remain at a constant level, the higher the price, the lower is the quantity demanded. As a result, demand of very high priced products will be on decline. Hence the price of the product plays a very crucial role in inventory analysis. In recent years, a number of industries have used various innovative pricing strategies viz., creative pricing schemes on internet sales, two-part tariffs, bundling, peak-load pricing and dynamic pricing, to boost the market demand and to manage their inventory effectively. The

* Corresponding author. Tel/Fax: 91-11-27666672

E-mail: ckjaggi@yahoo.com, ckjaggi@or.du.ac.in (C. K. Jaggi)

(C) 2014 Growing Science Ltd. All rights reserved.

doi: $10.5267 /$ j.ijiec.2014.9.001 
analysis on such inventory system with price-dependent demand was studied by (Cohen, 1977; Aggarwal \& Jaggi, 1989; Wee, 1997, 1999; Mukhopadhyay et al., 2004, 2005; Jaggi \& Verma, 2008; Jaggi et al., 2010, Jaggi et al., 2014) and many more.

It is factual for all the business firms that right pricing strategy helps to get hold of more customers, which increases revenues for the firm by increasing its demand. Now in order to satisfy the stupendous demand, the firm needs to stock a higher inventory, which, for obvious reason requires an additional storage space other than its owned warehouse $(\mathrm{OW})$. The additional storage space required by the organization to store the surplus inventory is called as rented warehouse (RW), which is assumed to be of abundant capacity. Usually the holding cost in RW is higher than that in OW due to the availability of better preserving facility, which results a lower deterioration for the goods than OW. To reduce the inventory costs, it would be economical to consume the goods of RW at the earliest. As a result, the stocks of OW will not be released until the stocks of RW are exhausted. This approach is termed as Last-In-First-Out (LIFO) approach. Nevertheless, in today's economical markets, warehouse rentals can be very deceiving since due to competition various warehouses offer very reasonable rates, which may be low as that of OW. In such a case, organizations adopt the First-In-First-Out (FIFO) dispatching policy, which also yields fresh and good conditioned stock thereby resulting in more customer satisfaction, especially when items are deteriorating in nature. Thus, making the right choice for the dispatching policy should be a key business objective for the organization that thrives on their products as a way to satisfy customers.

Owing of these facts, the researchers have devoted a great effort in the two-warehouse inventory systems. The pioneer models in this area were given by Hartely (1976) and Sarma (1983). Thereafter several interesting papers have been published by different researchers (Lee, 2006; Hsieh et al., 2008; Niu \& Xie, 2008; Rong et al., 2008; Lee \& Hsu, 2009; Jaggi et al., 2011).

Moreover in the prevailing economy, the effects of inflation and time value of money cannot be ignored; as it increases the cost of goods. When the general price level rises, each unit of currency buys fewer goods and services; consequently, inflation is also a decline in the real value of money - a loss of purchasing power in the medium of exchange which is also the monetary unit of account in the economy. Further, from a financial standpoint, an inventory represents a capital investment and must compete with other assets for a firm's limited capital funds. And, rising inflation directly affects the financial situation of an organization. Thus, while determining the optimal inventory policy the effect of inflation should be considered. In the past many authors have developed different inventory models under inflationary conditions with different assumptions. In 1975, Buzacott developed an economic order quantity model under the impact of inflation. Bierman and Thomas (1977) proposed the EOQ model considering the effect of both inflation and time value of money. (Yang, 2004) developed an inventory model for deteriorating items with constant demand rate under inflationary conditions in a two warehouse inventory system and fully backlogged shortages. Several other researchers have worked in this area like (Jaggi et al., 2006; Dey et al., 2008; Jaggi \& Verma 2010). Recently, Jaggi et al. (2013) presented the effect of FIFO and LIFO dispatching policies in a two warehouse environment for deteriorating items under inflationary conditions with fully backlogged shortages.

The characteristic of all of the above articles is that the unsatisfied demand (due to shortages) is completely backlogged. However, in reality, demands for foods, medicines, etc. are usually lost during the shortage period. Generally it is observed for fashionable items and high-tech products with short product life cycle, the willingness for a customer to wait for backlogging during a shortage period is diminishing with the length of the waiting time. Hence, the longer the waiting time, the smaller the backlogging rate. (Abad, 1996) first developed a pricing and ordering policy for a variable rate of deterioration with partially backlogged shortages. Later to reflect this phenomenon, (Yang, 2006) modified (Yang, 2004) model for partially backlogged shortages. Dye et al. (2007) modified the (Abad, 1996) model taking into consideration the backorder cost and lost sale. Shah and Shukla (2009) also developed a deterministic inventory model for deteriorating items with partially backlogged shortages. 
Further, (Yang, 2012) extended (Yang, 2006) model for the three-parameter Weibull deterioration distribution. Recently, Jaggi et al. (2013) explored the effect of FIFO and LIFO dispatching policies in a two warehouse inventory system for deteriorating items with partially backlogged shortages.

This paper aims to develop an inventory model for deteriorating items in a two warehouse system with price dependent demand under inflationary conditions. Moreover, the model considers partially backlogged shortages, where the backlogging rate decreases exponentially as the waiting time increases. Further, we have investigated the application of FIFO and LIFO dispatching policies in different scenarios in the model. The main purpose of the present model is to determine the optimal inventory and pricing strategies, so as to maximize the total average profit of the system. Finally, numerical examples and sensitivity analysis have been presented to illustrate the applicability of FIFO and LIFO dispatch policies in different scenarios. These findings eventually serve as a ready reckoner for the organization to take appropriate decision under the prevailing environment.

\section{Assumptions and Notations}

The following assumptions and notations have been used in this paper.

\subsection{Assumptions:}

1. The demand rate $D(P)$, is assumed to be dependent on the selling price and of form, $D(p)=k p^{-e}$ where $k$ and $e$ are positive constants.

2. Replenishment rate is instantaneous.

3. The time horizon of the inventory system is infinite.

4. Lead time is negligible.

5. Inflation rate is constant.

6. The OW has a fixed capacity of $W$ units and RW has unlimited capacity.

7. The units in RW are kept only after the capacity of OW has been utilized completely.

8. During stock-out period, the backlogging rate is variable and is dependent on the length of the waiting time for next replenishment. So that the backlogging rate for the negative inventory is $e^{-\delta(T-t)}$ where $\delta(>0)$ denotes the backlogging parameter and $(T-t)$ is waiting time during $t_{1} \leq t \leq T$.

\subsection{Notations}

$Q_{r}(t), Q_{o}(t)$ : instantaneous inventory level at the time $t$ in RW and $\mathrm{OW}$, respectively

$Q_{F}, Q_{L} \quad$ : the replenishment quantity per replenishment in FIFO and LIFO model, respectively

$S_{F} S_{L} \quad:$ highest stock level at the beginning of the cycle in FIFO and LIFO model, respectively

A : ordering cost per order

$W \quad$ : storage capacity of OW

$\alpha, \beta \quad$ : deterioration rates in OW and RW respectively and $0<\alpha, \beta<<1$

$r \quad:$ discount rate, representing the time value of money

$i \quad$ : inflation rate

$R \quad: r-i$, representing the net discount rate of inflation is constant

c : purchase cost per unit quantity of item 
$p(p>c) \quad$ : selling price per unit of item

D : demand rate

$H, F \quad$ : holding cost per unit per unit time at OW and RW respectively

$\pi$

: the shortage cost per unit per unit time

$\pi_{L} \quad:$ the lost sale cost per unit per unit time

$\delta \quad$ : backlogging parameter

$T \quad$ : cycle length

$t_{w} \quad:$ the time at which inventory level reaches zero in OW for FIFO model

$t_{1} \quad:$ the time at which inventory level reaches zero in RW for FIFO model

$t_{w} \quad:$ the time at which inventory level reaches zero in RW for LIFO model

$t_{1} \quad:$ the time at which inventory level reaches zero in OW for LIFO model

TP : the present worth of total average profit

\section{Model description and analysis}

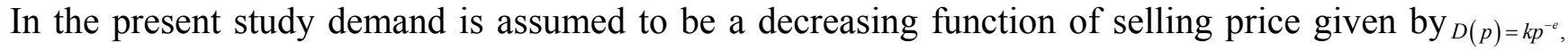
where $k$ and $e$ are positive constants. Shortages are allowed to accumulate in the model but are partially backlogged. Moreover a two warehouse inventory model has been devised, where the OW has a fixed capacity of $W$ units and the RW has unlimited capacity. The units in RW are stored only when the capacity of OW has been utilized completely. However, in such a scenario organization has an option to adopt either FIFO or LIFO dispatching policy. The following sections discuss the model formulation for both the policies.

\subsection{FIFO model formulation}

The behaviour of the model over the time interval $(0, T)$ has been represented graphically in (Figure 1). Initially a lot size of $Q_{F}$ units enters the system. After meeting the backorders, $S_{F}$ units enter the inventory system, out of which $W$ units are kept in OW and the remaining $Z=\left(S_{F}-W\right)$ units are kept in the RW. In this case as FIFO policy is being implemented, therefore the goods of the RW are consumed only after consuming the goods in OW. Starting from the initial stage till $t_{w}$, the time the inventory in OW is depleted first due to the combined effect of demand and deterioration and the inventory level in RW also reduces from $Z$ to $Z^{0}$ due to effect of deterioration. At time $t_{w}$ OW gets exhausted. Further, during the interval $\left(t_{w}, t_{1}\right)$ depletion due to demand and deterioration will occur simultaneously in the RW and it reaches to zero at time $t_{1}$. Moreover, during the interval $\left(t_{1}, T\right)$ some part of the demand is backlogged and the rest is lost. The quantity to be ordered will be $Q_{F}=S_{F}+D\left(T-t_{1}\right)$.

During the time interval $\left(0, t_{w}\right)$ the inventory level in the OW decreases due to the combined effect of both the demand and deterioration. The differential equation representing the inventory level in the OW during this interval is given by 


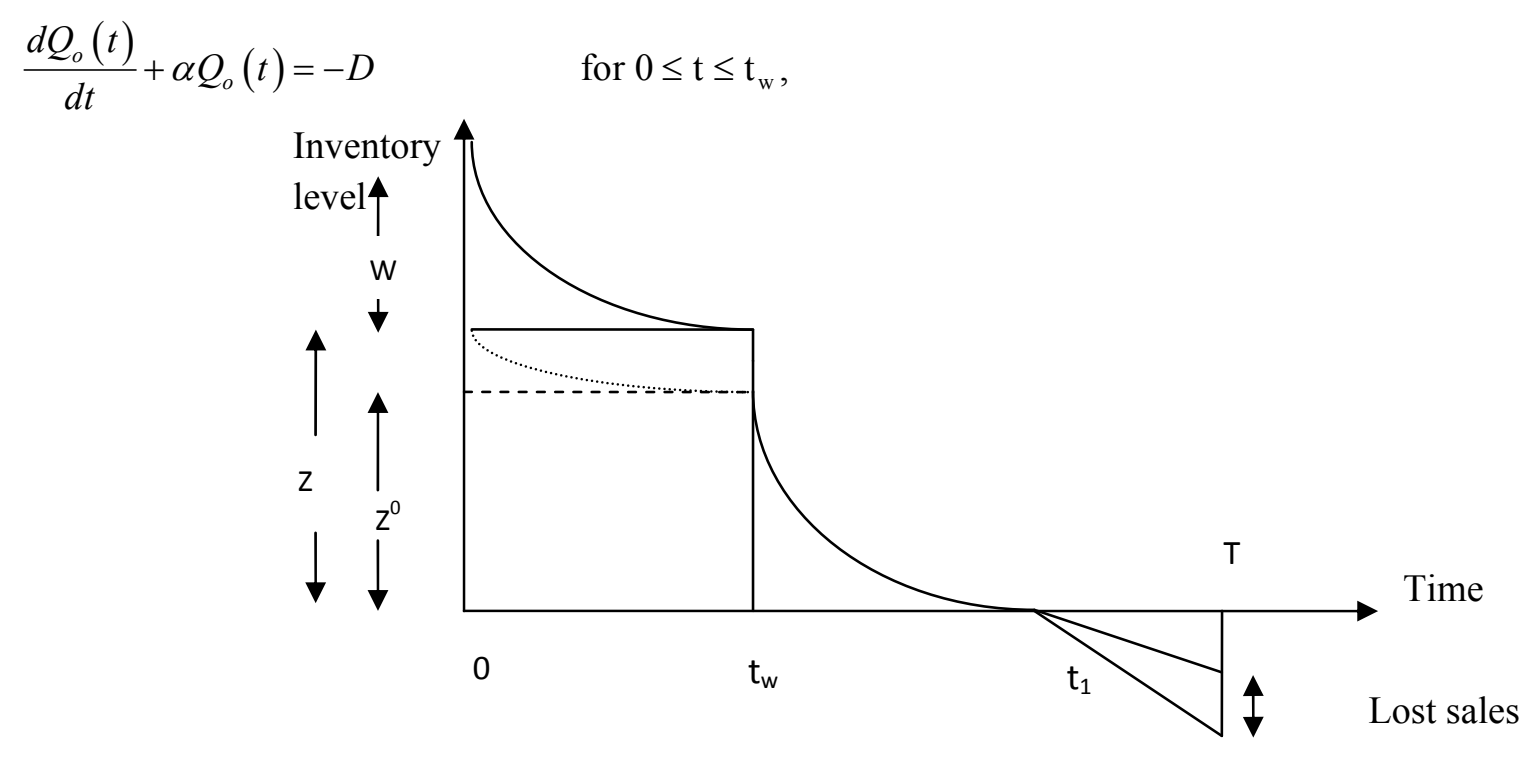

Fig. 1. Graphical representation of two warehouse inventory system for FIFO policy with the initial condition $Q_{0}(0)=W$, the solution is given by

$Q_{o}(t)=\left(W+\frac{D}{\alpha}\right) \mathrm{e}^{-\alpha t}-\frac{D}{\alpha} \quad$ for $0 \leq \mathrm{t} \leq \mathrm{t}_{\mathrm{w}}$

Noting that at $t=t_{w}, Q_{0}(t)=0$ we get

$t_{w}=\frac{1}{\alpha} \log \left(1+\frac{\alpha W}{D}\right)$

Now, during the interval $\left(0, t_{w}\right)$, the inventory level $Z$ kept in RW also depletes to a level $Z^{0}$ due to the effect of deterioration. Hence, the differential equation below represent the inventory level in this interval is given by

$\frac{d Q_{r}(t)}{d t}+\beta Q_{r}(t)=0 \quad$ for $0 \leq \mathrm{t} \leq \mathrm{t}_{\mathrm{w}}$,

using the boundary condition $Q_{r}(0)=Z$, the solution is

$Q_{r}(t)=Z e^{-\beta t}, \quad$ for $0 \leq \mathrm{t} \leq \mathrm{t}_{\mathrm{w}}$,

Now at $t=t_{w}, Q_{r}\left(t_{w}\right)=Z^{0}$ we have

$Z^{0}=Z e^{-\beta t_{w}}$

Again, during the time interval $\left(t_{w}, t_{1}\right)$, the inventory level in RW decreases due to the combined effect of demand and deterioration both. The differential equation describing the inventory level this interval is given by

$\frac{d Q_{r}(t)}{d t}+\beta Q_{r}(t)=-D, \quad$ for $\mathrm{t}_{\mathrm{w}} \leq t \leq t_{1}$

using the boundary condition $Q_{r}\left(t_{w}\right)=Z^{0}$, the solution is

$Q_{r}(t)=\frac{-D}{\beta}+\left(Z^{0}+\frac{D}{\beta}\right) \mathrm{e}^{\beta\left(t_{w}-t\right)}, \quad$ for $\mathrm{t}_{\mathrm{w}} \leq t \leq t_{1}$ 
Noting that at $t=t_{1}, Q_{r}(t)=0$ and we get

$t_{1}=t_{w}+\frac{1}{\beta} \log \left(1+\frac{\beta Z^{0}}{D}\right)$

Now at time $t_{1}$ inventory is exhausted in both the warehouses, so after time $t_{1}$ shortages start to accumulate. It is assumed that during the time $\left(t_{1}, T\right)$, only some fraction i.e. $e^{-\delta(T-t)}$ of the total shortages is backlogged while the rest is lost, where $t \in\left(t_{1}, T\right)$. Hence, the shortage level at time $t$ is represented by the following differential equation:

$\frac{d S(t)}{d t}=-D e^{-\delta(T-t)}, \quad$ for $\mathrm{t}_{1} \leq \mathrm{t} \leq \mathrm{T}$

After using the boundary condition $S\left(t_{1}\right)=0$, the solution is given by

$S(t)=\frac{D}{\delta}\left\{e^{-\delta\left(T-t_{1}\right)}-e^{-\delta(T-t)}\right\}$

Since, demand is considered as a function of selling price and shortages are partially backlogged. Hence, by using continuous compounding of inflation and discount rate, the present worth of the various costs during the cycle $(0, T)$ is evaluated as follows:

(a) Present worth of the ordering cost is

$O C=A$

(b) Present worth of the inventory holding cost in RW is

$H C_{r w}=\int_{0}^{t_{w}} F e^{-R t} Q_{r}(t) d t+\int_{t_{w}}^{t_{1}} F e^{-R t} Q_{r}(t) d t$
$H C_{r w}=\frac{F}{R(R+\beta)}\left\{Z R+D\left(e^{-R t_{1}}-e^{-R t_{w}}\right)\right\}$

(c) Present worth of the inventory holding cost in OW is

$H C_{o w}=\int_{0}^{t_{w}} H e^{-R t} Q_{o}(t) d t$

$H C_{o w}=\frac{H}{R(R+\alpha)}\left\{R W+D\left(e^{-R t_{w}}-1\right)\right\}$

(d) Present worth of the backlogging cost is

$$
\begin{aligned}
& S C=\int_{t_{1}}^{T}-\pi e^{-R t}\{S(t)\} d t \\
& S C=\int_{t_{1}}^{T}-\pi e^{-R t}\left\{\frac{D}{\delta}\left(e^{-\delta\left(T-t_{1}\right)}-e^{-\delta(T-t)}\right)\right\} d t \\
& S C=\frac{\pi D}{\delta}\left[\frac{e^{-\delta T}}{(\delta-R)}\left\{e^{(\delta-R) T}-e^{(\delta-R) t_{1}}\right\}-\frac{e^{-\delta\left(T-t_{1}\right)}}{R}\left(e^{-R t_{1}}-e^{-R T}\right)\right]
\end{aligned}
$$

(e) Present worth of the opportunity cost due to lost sales is

$$
\begin{aligned}
& L S=e^{-R T} \int_{t_{1}}^{T} \pi_{L} D\left(1-e^{-\delta(T-t)}\right) d t \\
& L S=\pi_{L} D e^{-R T}\left\{\left(T-t_{1}\right)-\frac{1}{\delta}\left(1-e^{-\delta\left(T-t_{1}\right)}\right)\right\}
\end{aligned}
$$


(f) Present worth of the purchase cost is

$P C=c Q_{F}$

$P C=c\left\{S_{F}+D\left(T-t_{1}\right)\right\}$

(g) Present worth of sales revenue is

$S R=p\left\lfloor\int_{0}^{t_{1}} D e^{-R t} d t+e^{-R T} \int_{t_{1}}^{T} D e^{-\delta(T-t)} d t\right\rfloor$

$S R=p D\left[\frac{1}{R}\left(1-e^{-R t_{1}}\right)+\frac{e^{-R T}}{\delta}\left(1-e^{-\delta\left(T-t_{1}\right)}\right)\right]$

Now, the present worth of the total average profit during the cycle $(0, T), T P\left(S_{F}, p\right)$ is thus given by the following expression:

$T P\left(S_{F}, p\right)=\frac{1}{T}\left[S R-O C-H C_{r w}-H C_{o w}-S C-L S-P C\right]$

After substituting the values of these from Eqs. (12-18), Eq. (19) reduces to the present worth of the total average profit for the system

$$
T P\left(S_{F}, p\right)=\frac{1}{T}\left[\begin{array}{l}
p D\left\{\frac{1}{R}\left(1-e^{-R t_{t}}\right)+\frac{e^{-R T}}{\delta}\left(1-e^{-\delta\left(T-t_{t}\right)}\right)\right\}-A-\frac{F}{R(R+\beta)}\left\{Z R+D\left(e^{-R_{t_{t}}}-e^{-R_{t_{w}}}\right)\right\} \\
-\frac{H}{R(R+\alpha)}\left\{R W+D\left(e^{-R_{t_{i}}}-1\right)\right\}-\frac{\pi D}{\delta}\left[\frac{e^{-\delta T}}{(\delta-R)}\left\{e^{(\delta-R) T}-e^{(\delta-R)_{t_{1}}}\right\}-\frac{e^{-\delta\left(T-t_{t}\right)}}{R}\left(e^{-R t_{t}}-e^{-R T}\right)\right] \\
-\pi_{L} D e^{-R T}\left\{\left(T-t_{1}\right)-\frac{1}{\delta}\left(1-e^{-\delta\left(T-t_{1}\right)}\right)\right\}-\mathcal{C}\left\{S_{F}+D\left(T-t_{1}\right)\right\}
\end{array}\right]
$$

Substituting the values of $t_{1}$ from Eq. (9), we get

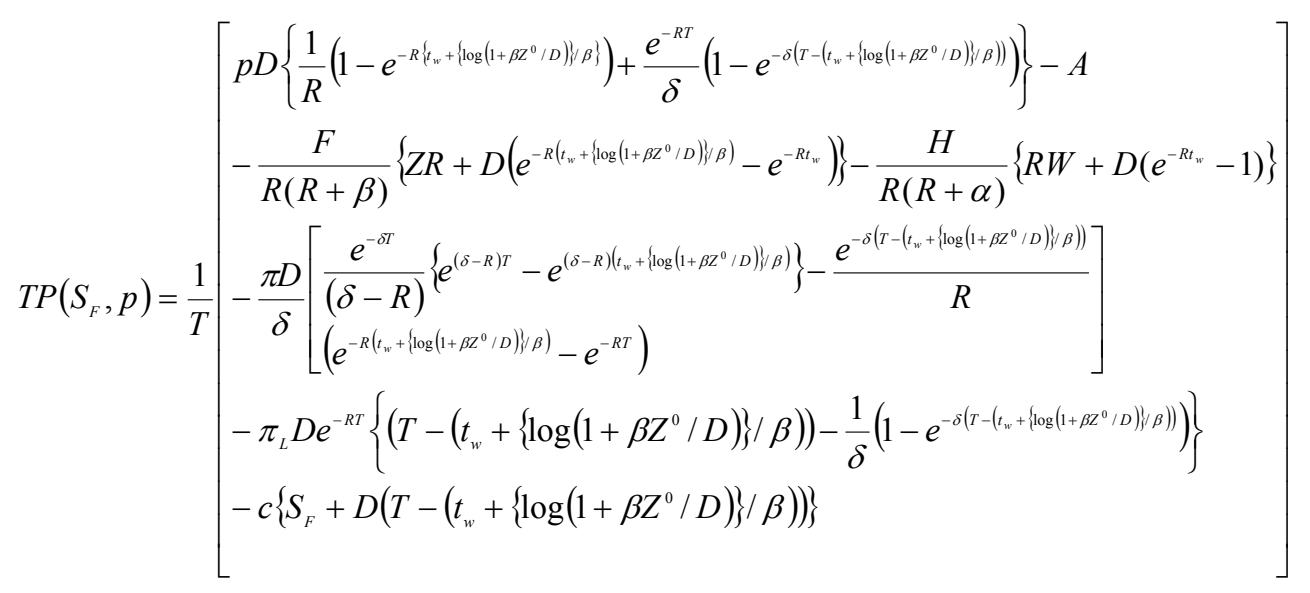

\subsection{Solution Procedure}

Our objective is to maximize the present worth of total average profit. The necessary conditions for maximizing the present worth of total average profit are given by

$$
\frac{\partial T P\left(S_{F}, p\right)}{\partial S_{F}}=0, \frac{\partial T P\left(S_{F}, p\right)}{\partial p}=0
$$




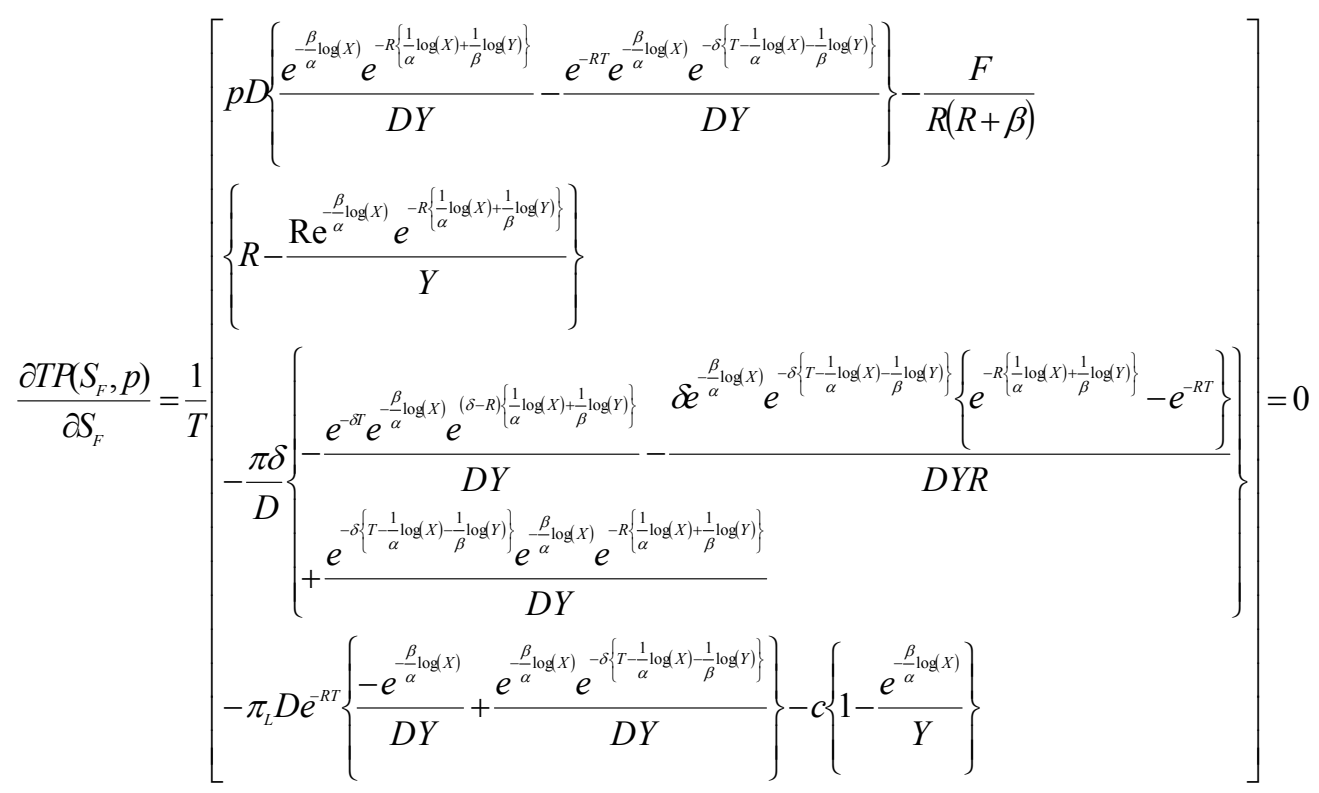

where $X=\left(1+\frac{\alpha W}{D}\right), \mathrm{Y}=\left(1+\frac{\left(\mathrm{S}_{\mathrm{F}}-W\right) e^{-\frac{\beta}{\alpha} \log (X)} \beta}{D}\right)$ and $\mathrm{D}=\mathrm{kp}^{-\mathrm{e}}$.

$\frac{\partial T P\left(S_{F}, p\right)}{\partial p}=\frac{1}{T}\left[k p^{-e}\left\{\frac{1-e^{-R\left(\frac{1}{\alpha} \log (X)+\frac{1}{\beta} \log (Y)\right)}}{R}+\frac{e^{-R T}\left\{1-e^{-\delta\left(T-\frac{1}{\alpha} \log (X)-\frac{1}{\beta} \log (Y)\right)}\right\}}{\delta}\right\}-k p^{-e} e\left\{\begin{array}{l}\frac{1-e^{-R\left(\frac{1}{\alpha} \log (X)+\frac{1}{\beta} \log (Y)\right)}}{R} \\ e^{-R T}\left\{1-e^{-\delta\left(T-\frac{1}{\alpha} \log (X)-\frac{1}{\beta} \log (Y)\right)}\right\} \\ \left.+\frac{\delta}{\delta}\right\}\end{array}\right\}\right.$

$\left.+p k p^{-e}\left\{\begin{array}{l}\left(\begin{array}{l}\frac{W e}{k p^{-e} p X}+\frac{-\left(S_{F}-W\right) \beta^{2} W e e^{-\frac{\beta}{\alpha} \log (X)}}{k^{2}\left(p^{-e}\right)^{2} p X}+\frac{\left(S_{F}-W\right) e^{-\frac{\beta}{\alpha} \log (X)} \beta e}{k p^{-e} p} \\ \beta Y\end{array}\right) e^{-R\left(\frac{1}{\alpha} \log (X)+\frac{1}{\beta} \log (Y)\right)} \\ +e^{-R T}\left(\begin{array}{l}\frac{W e}{k p^{-e} p X}+\frac{-\left(S_{F}-W\right) \beta^{2} W e e^{-\frac{\beta}{\alpha} \log (X)}}{k^{2}\left(p^{-e}\right)^{2} p X}+\frac{\left(S_{F}-W\right) e^{-\frac{\beta}{\alpha} \log (X)} \beta e}{k p^{-e} p} \\ \beta Y\end{array}\right.\end{array}\right\} e^{-\delta\left(T-\frac{1}{\alpha} \log (X)-\frac{1}{\beta} \log (Y)\right)}\right\}$

$-\frac{F}{R(R+\beta)}\left\{\begin{array}{l}-k p^{-e} e\left(e^{-R\left(\frac{1}{\alpha} \log (X)+\frac{1}{\beta} \log (Y)\right)}-e^{-\frac{\beta}{\alpha} \log (X)}\right) \\ p\end{array} k p^{-e}\left\{-R\left(\frac{W e}{k p^{-e} p X}+\frac{\left.\frac{-\left(S_{F}-W\right) \beta^{2} W e e^{-\frac{\beta}{\log (X)}}}{k^{2}\left(p^{-e}\right)^{2} p X}+\frac{\left(S_{F}-W\right) e^{-\frac{\beta}{\alpha} \log (X)} \beta e}{k p^{-e} p}\right)}{\beta Y}\right)\right\}\right\}$ 


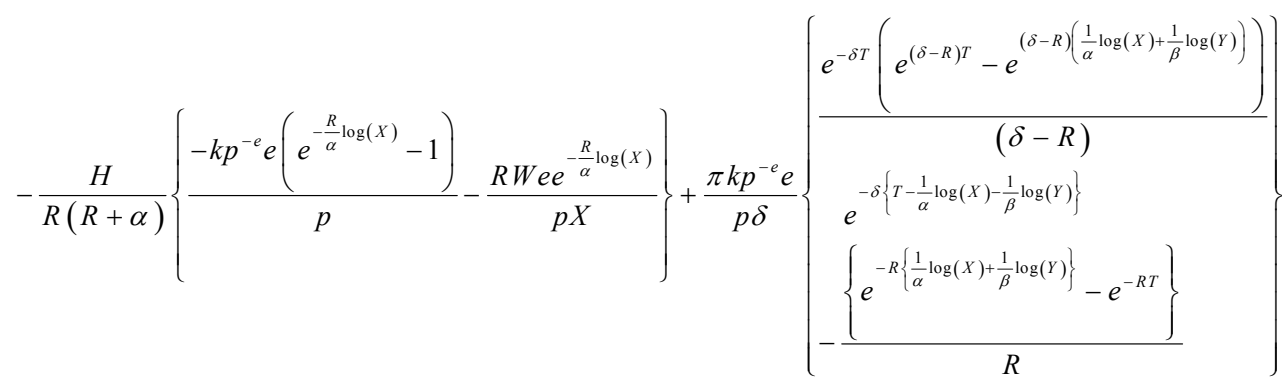

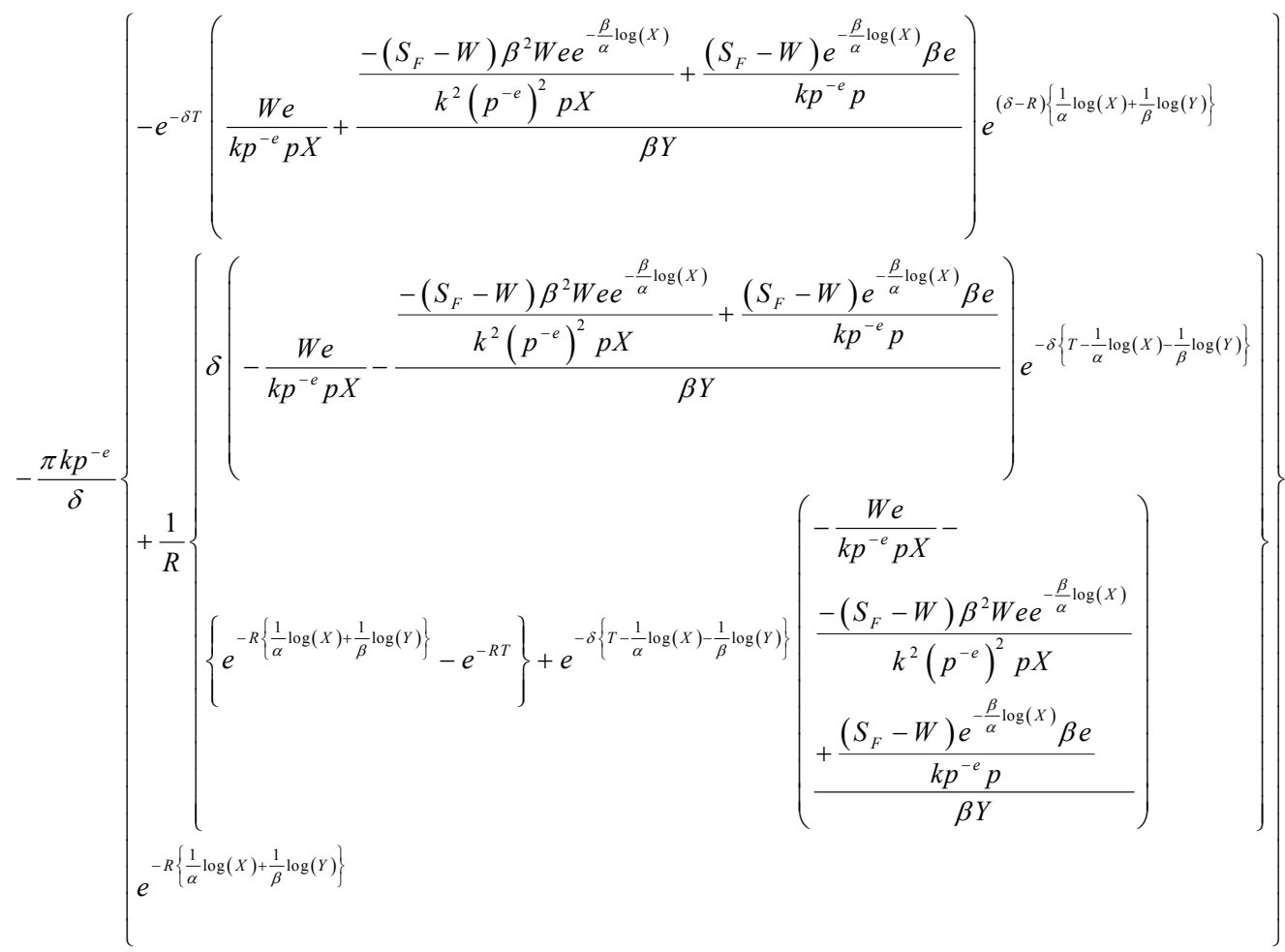

$+\frac{\pi_{L} k p^{-e} e e^{-R T}\left\{T-\frac{1}{\alpha} \log (X)-\frac{1}{\beta} \log (Y)-\frac{1-e^{-\delta\left\{T-\frac{1}{\alpha} \log (X)-\frac{1}{\beta} \log (Y)\right\}}}{\delta}\right\}}{p}$

$-\pi_{L} k p^{-e} e^{-R T}\left\{\begin{array}{l}-\frac{W e}{k p^{-e} p X}-\frac{\frac{-\left(S_{F}-W\right) \beta^{2} W e e^{-\frac{\beta}{\alpha} \log (X)}}{k^{2}\left(p^{-e}\right)^{2} p X}+\frac{\left(S_{F}-W\right) e^{-\frac{\beta}{\alpha} \log (X)} \beta e}{k p^{-e} p}}{\beta Y} \\ -\frac{W e}{k p^{-e} p X} \\ -\frac{-\left(S_{F}-W\right) \beta^{2} W e e^{-\frac{\beta}{\alpha} \log (X)}}{k^{2}\left(p^{-e}\right)^{2} p X}+\frac{\left(S_{F}-W\right) e^{-\frac{\beta}{\alpha} \log (X)} \beta e}{k p^{-e} p} \\ -\frac{\beta Y}{-\delta\left\{T-\frac{1}{\alpha} \log (X)-\frac{1}{\beta} \log (Y)\right\}}\end{array}\right\}$

$-c\left\{\frac{-k p^{-e} e\left(T-\frac{1}{\alpha} \log (X)-\frac{1}{\beta} \log (Y)\right)}{p}+k p^{-e}\left(-\frac{W e}{k p^{-e} p X}-\frac{\frac{-\left(S_{F}-W\right) \beta^{2} W e e^{-\frac{\beta}{\alpha} \log (X)}}{k^{2}\left(p^{-e}\right)^{2} p X}+\frac{\left(S_{F}-W\right) e^{-\frac{\beta}{\alpha} \log (X)} \beta e}{k p^{-e} p}}{\beta Y}\right)\right\}=0$

where $X=\left(1+\frac{\alpha W}{k p^{-e}}\right)$ and $\mathrm{Y}=\left(1+\frac{\left(\mathrm{S}_{\mathrm{F}}-W\right) e^{-\frac{\beta}{\log (X)} \beta}}{k p^{-e}}\right)$

which gives the optimal values of $S_{F}$ and $p$. 
Further, for the present worth of total average profit, $\operatorname{TP}\left(S_{F}, p\right)$ to be concave, the following sufficient condition must be satisfied

$$
\frac{\partial^{2} T P\left(S_{F}, p\right)}{\partial S_{F}{ }^{2}} \leq 0, \frac{\partial^{2} T P\left(S_{F}, p\right)}{\partial p^{2}} \leq 0
$$

Since, the second derivative of the present worth of total average profit $\operatorname{TP}\left(S_{F}, p\right)$ is complicated and it is very difficult to prove concavity mathematically. Thus, the concavity of the present worth of total average profit has been established graphically (on several data sets) which is shown below. (Figure 2)

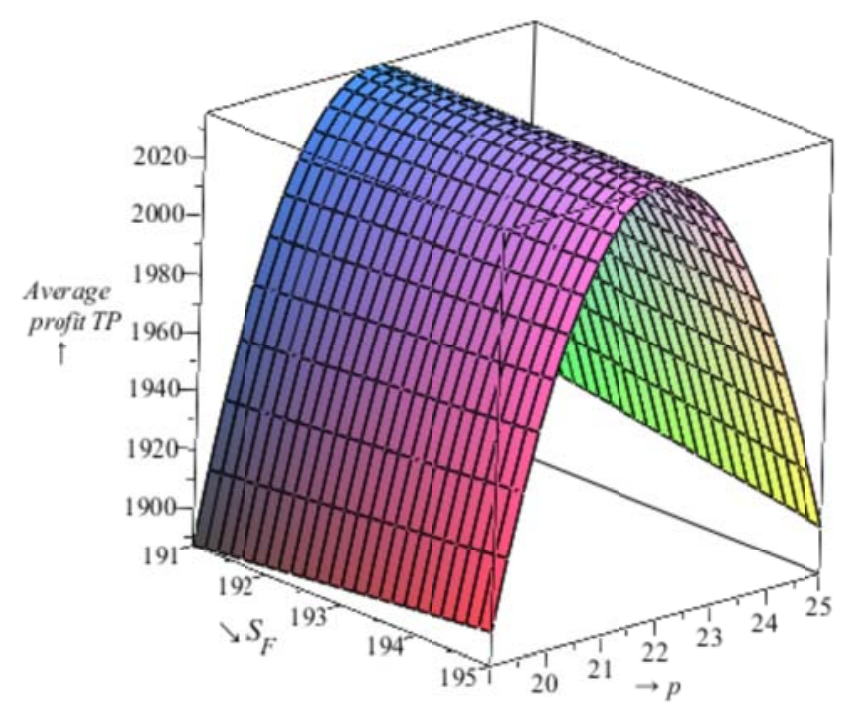

Fig. 2. Average profit versus $S_{F}$ and $p$ for FIFO policy

\subsection{LIFO model formulation}

The behaviour of the model over the time interval $(0, T)$ has been represented graphically in (Fig. 3). Initially a lot size of $Q_{L}$ units enters the system. After meeting the backorders, $S_{L}$ units enter the inventory system, out of which $W$ units are kept in OW and the remaining $Z=\left(S_{L}-W\right)$ units are kept in the RW. In this case as LIFO policy is being implemented, therefore the goods of the OW are consumed only after consuming the goods in RW. Starting from the initial stage till $t_{w}$, the time the inventory in RW is depleted first due to the combined effect of demand and deterioration and the inventory level in OW also reduces from $W$ to $W^{0}$ due to effect of deterioration. At time $t_{w}$ RW gets exhausted. Further, during the interval $\left(t_{w}, t_{1}\right)$ depletion due to demand and deterioration will occur simultaneously in the OW and it reaches to zero at time $t_{1}$. Moreover, during the interval $\left(t_{1}, T\right)$ some part of the demand is backlogged and the rest is lost. The quantity to be ordered will be $Q_{L}=D\left(T-t_{1}\right)+S_{L}$.

During the time interval $\left(0, t_{w}\right)$ the inventory level in the RW decreases due to the combined effect of both the demand and deterioration. The differential equation representing the inventory level in the RW during this interval is given by 
Inventory level

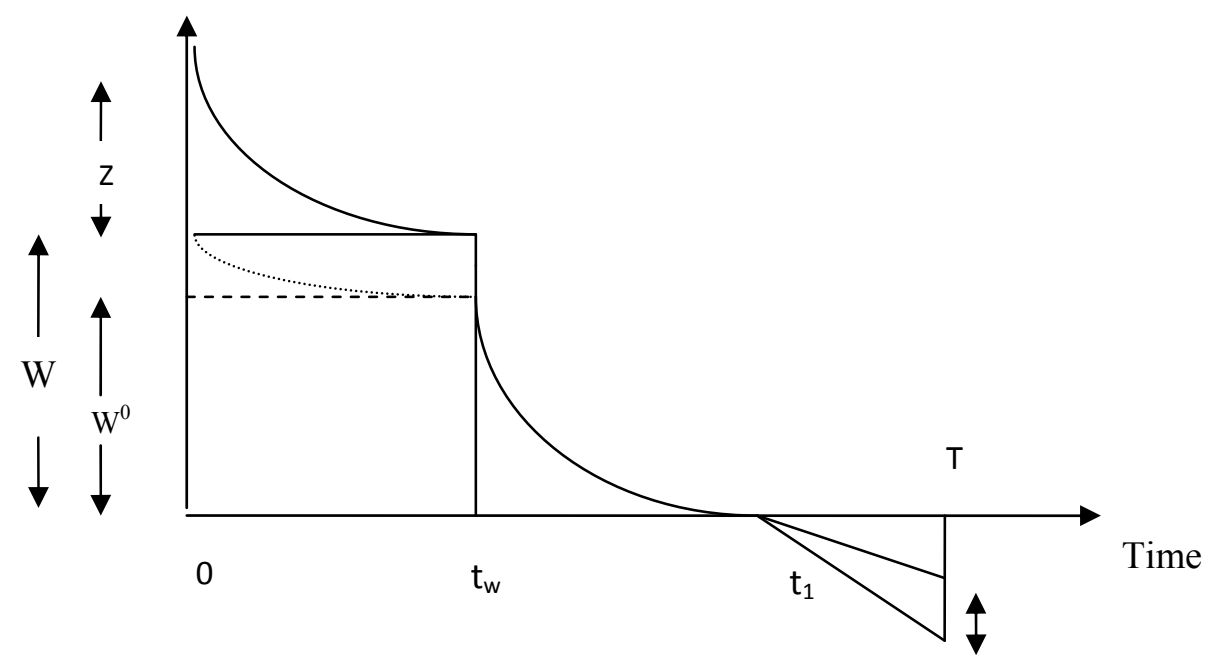

Lost sales

Fig. 3. Graphical representation of two warehouse inventory system for LIFO policy

$\frac{d Q_{r}(t)}{d t}+\beta Q_{r}(t)=-D, \quad$ for $0 \leq t \leq t_{w}$

and using the initial condition $Q_{r}(0)=Z$ the solution is

$Q_{r}(t)=\left(Z+\frac{D}{\beta}\right) \mathrm{e}^{-\beta t}-\frac{D}{\beta} \quad$ for $0 \leq t \leq t_{w}$

Noting that at $t=t_{w}, Q_{r}(t)=0$ we get

$t_{w}=\frac{1}{\beta} \log \left(1+\frac{\beta Z}{D}\right)$

Now, during the interval $\left(0, t_{w}\right)$, the inventory $W$ kept in OW also reduces from $W$ to $W^{0}$ due to the effect of deterioration. Hence, the differential equation below represent the inventory level in this interval is given by

$\frac{d Q_{o}(t)}{d t}+\alpha Q_{o}(t)=0 \quad$ for $0 \leq \mathrm{t} \leq \mathrm{t}_{\mathrm{w}}$,

After using the boundary condition $Q_{o}(0)=W$, the solution is

$Q_{o}(t)=W e^{-\alpha t} \quad$ for $0 \leq \mathrm{t} \leq \mathrm{t}_{\mathrm{w}}$

Now at $t=t_{w}, Q_{o}(t)=W^{0}$ we have

$W^{0}=W e^{-\alpha t_{w}}$

Again, during the time interval $\left(t_{w}, t_{1}\right)$, the inventory level in OW decreases due to the combined effect of demand and deterioration both. The differential equation describing the inventory level this interval is given by

$\frac{d Q_{o}(t)}{d t}+\alpha Q_{o}(t)=-D \quad$ for $\mathrm{t}_{\mathrm{w}} \leq \mathrm{t} \leq \mathrm{t}_{1}$ 
Using the boundary condition $Q_{o}\left(t_{w}\right)=W^{0}$, the solution is

$Q_{o}(t)=\left(W^{0}+\frac{D}{\alpha}\right) \mathrm{e}^{\alpha\left(t_{w}-t\right)}-\frac{D}{\alpha} \quad$ for $\mathrm{t}_{\mathrm{w}} \leq \mathrm{t} \leq \mathrm{t}_{1}$

Note that at $t=t_{1}, Q_{o}(t)=0$ we get,

$t_{1}=t_{w}+\frac{1}{\alpha} \log \left(1+\frac{\alpha W^{0}}{D}\right)$

Now at time $t_{1}$ inventory is exhausted in both the warehouses, so after time $t_{1}$ shortages start to accumulate. It is assumed that during the time $\left(t_{l}, T\right)$, only some fraction i.e. $e^{-\delta(T-t)}$ of the total shortages is backlogged while the rest is lost, where $t \in\left(t_{1}, T\right)$. Hence, the shortage level at time $t$ is represented by the following differential equation:

$\frac{d S(t)}{d t}=-D e^{-\delta(T-t)}, \quad$ for $\mathrm{t}_{1} \leq \mathrm{t} \leq \mathrm{T}$

After using the boundary condition $S\left(t_{1}\right)=0$, the solution is

$S(t)=\frac{D}{\delta}\left\{e^{-\delta\left(T-t_{1}\right)}-e^{-\delta(T-t)}\right\}$

Since, demand is considered as a function of selling price and shortages are partially backlogged. Hence, by using continuous compounding of inflation and discount rate, the present worth of the various costs during the cycle $(0, T)$ is evaluated as follows:

(a) Present worth of the ordering cost is

$O C=A$

(b) Present worth of the inventory holding cost in RW is

$H C_{r w}=\int_{0}^{t_{w}} F e^{-R t} Q_{r}(t) d t$

$H C_{r w}=\frac{F}{R(R+\beta)}\left\{Z R+D\left(e^{-R t_{w}}-1\right)\right\}$

(c) Present worth of the inventory holding cost in OW is

$H C_{o w}=\int_{0}^{t_{w}} H e^{-R t} Q_{o}(t) d t+\int_{t_{w}}^{t_{1}} H e^{-R t} Q_{o}(t) d t$
$H C_{o w}=\frac{H}{R(R+\alpha)}\left(W R+D\left(e^{-R t_{1}}-e^{-R t_{w}}\right)\right)$

(d) Present worth of the backlogging cost is

$S C=\int_{t_{1}}^{T}-\pi e^{-R t}\{S(t)\} d t$

$S C=\int_{t_{1}}^{T}-\pi e^{-R t}\left\{\frac{D}{\delta}\left(e^{-\delta\left(T-t_{1}\right)}-e^{-\delta(T-t)}\right)\right\} d t$

$S C=\frac{\pi D}{\delta}\left[\frac{e^{-\delta T}}{(\delta-R)}\left\{e^{(\delta-R) T}-e^{(\delta-R) t_{1}}\right\}-\frac{e^{-\delta\left(T-t_{1}\right)}}{R}\left(e^{-R t_{1}}-e^{-R T}\right)\right]$

(e) Present worth of the opportunity cost due to lost sales is 
$L S=e^{-R T} \int_{t_{1}}^{T} \pi_{L} D\left(1-e^{-\delta(T-t)}\right) d t$

$L S=\pi_{L} D e^{-R T}\left\{\left(T-t_{1}\right)-\frac{1}{\delta}\left(1-e^{-\delta\left(T-t_{1}\right)}\right)\right\}$

(f) Present worth of the purchase cost is

$P C=c Q_{L}$

$P C=c\left\{S_{L}+D\left(T-t_{1}\right)\right\}$

(g) Present worth of sales revenue is

$$
\begin{aligned}
& S R=p\left[\int_{0}^{t_{1}} D e^{-R t} d t+e^{-R T} \int_{t_{1}}^{T} D e^{-\delta(T-t)} d t\right] \\
& S R=p D\left[\frac{1}{R}\left(1-e^{-R t_{1}}\right)+\frac{e^{-R T}}{\delta}\left(1-e^{-\delta\left(T-t_{1}\right)}\right)\right]
\end{aligned}
$$

Now, the present worth of the total average profit during the cycle $(0, T), T P\left(S_{L}, p\right)$ is thus given by the following expression:

$T P\left(S_{L}, p\right)=\frac{1}{T}\left[S R-O C-H C_{r w}-H C_{o w}-S C-L S-P C\right]$

After substituting the values of these from Eqs. (35-41), Eq. (42) reduces to the present worth of the total average profit for the system

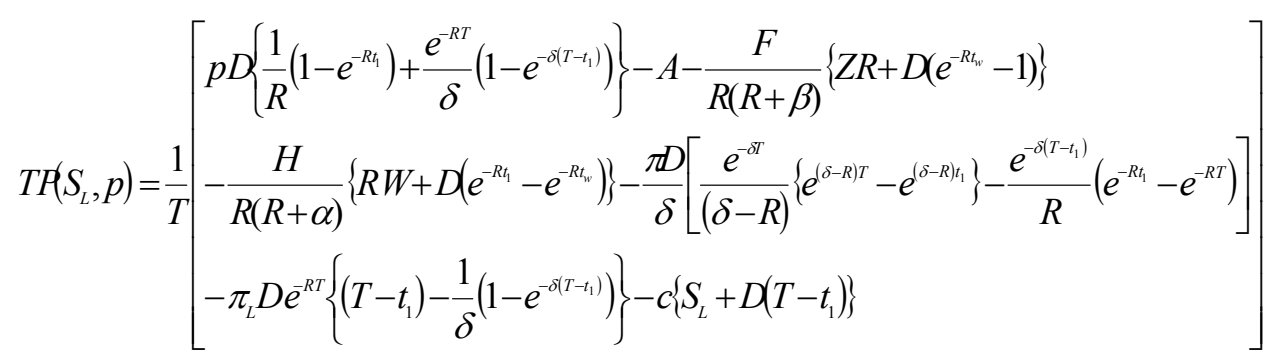

Substituting the values of $t_{w}$ and $t_{1}$ from Eq. (26) and Eq. (32) respectively, we get

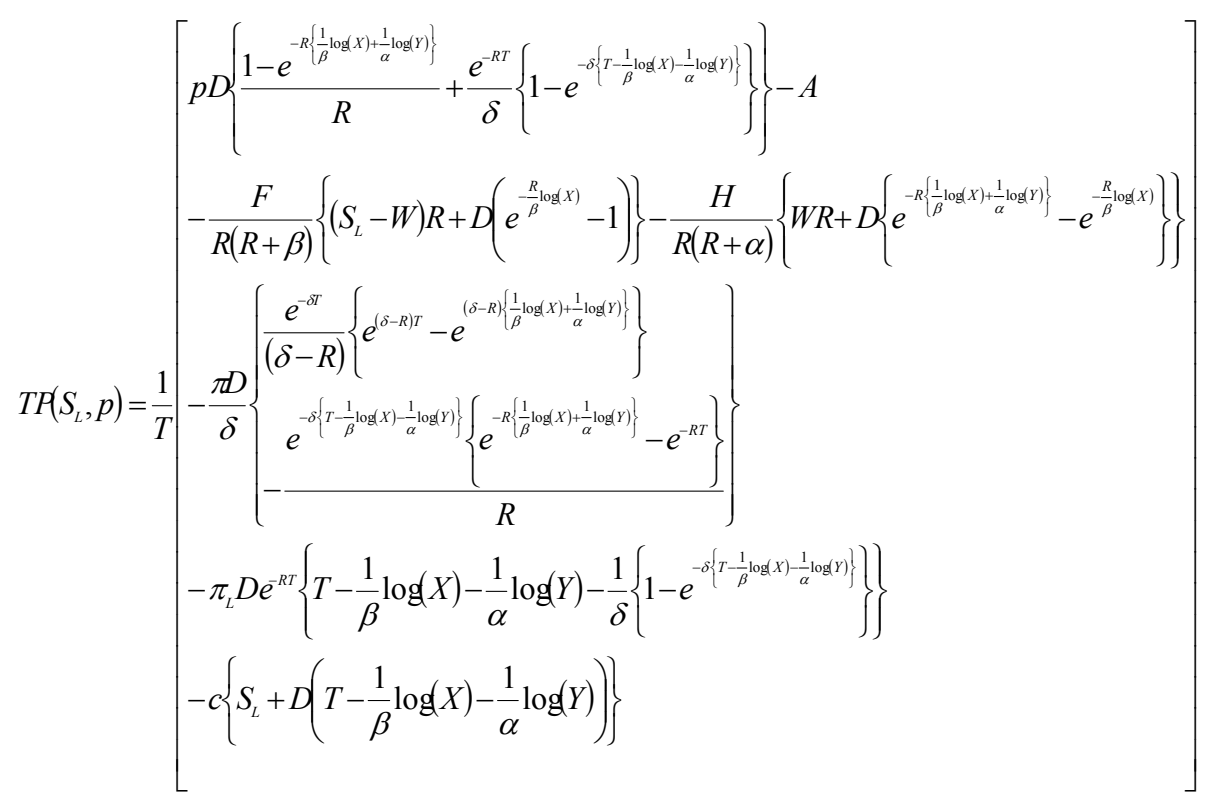


where $X=\left(1+\frac{\left(S_{L}-W\right) \beta}{D}\right)$ and $Y=\left(1+\frac{\alpha W e^{-\frac{\alpha}{\beta} \log \left(1+\frac{\left(S_{L}-W\right) \beta}{D}\right)}}{D}\right)$.

\subsection{Solution Procedure}

Our objective is to maximize the present worth of total average profit. The necessary conditions for maximizing the present worth of total average profit are given by

$$
\begin{aligned}
& \frac{\partial T P\left(S_{L}, p\right)}{\partial S_{L}}=0, \frac{\partial T P\left(S_{L}, p\right)}{\partial p}=0
\end{aligned}
$$

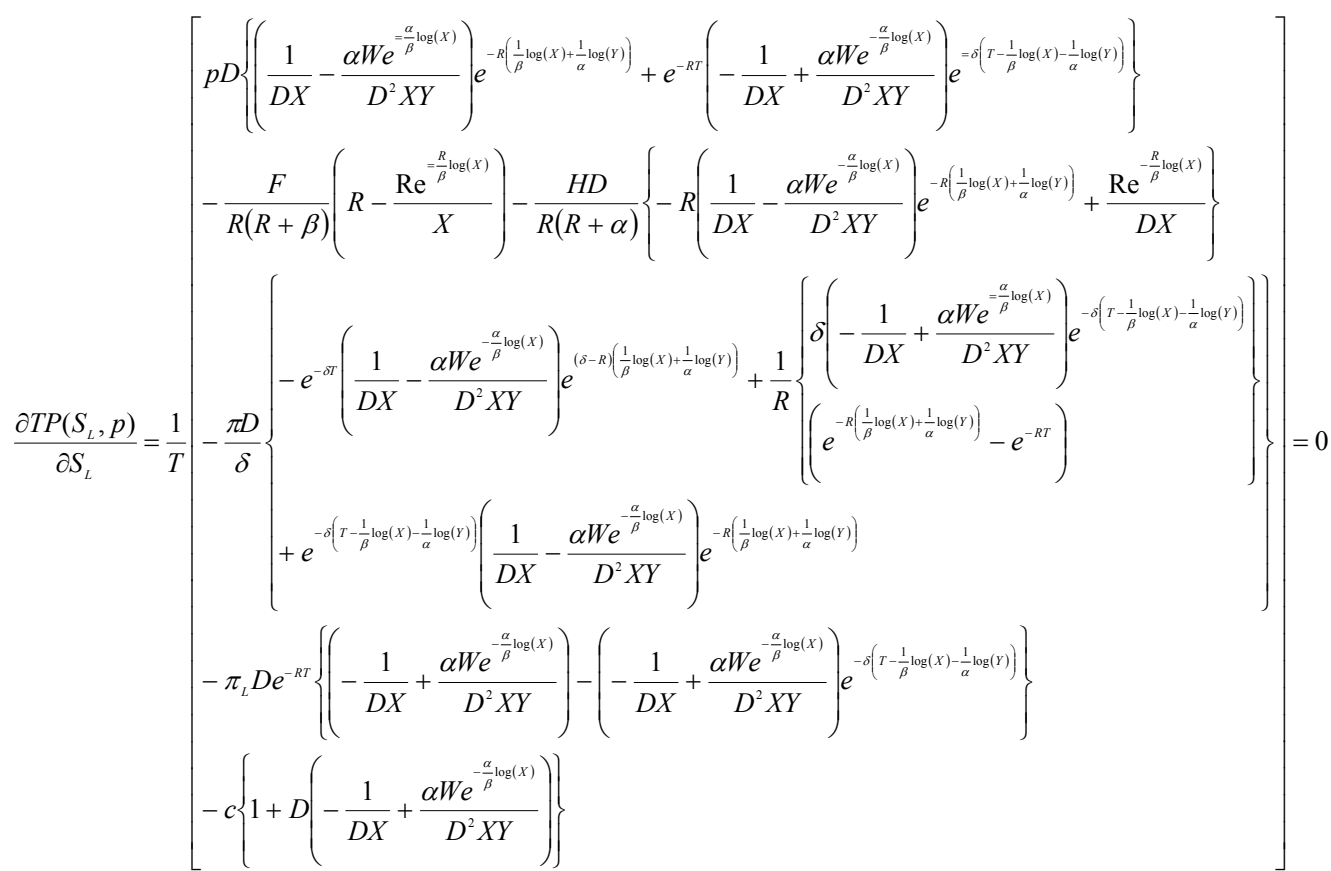

where $X=\left(1+\frac{\left(S_{L}-W\right) \beta}{D}\right), \mathrm{Y}=\left(1+\frac{\alpha W e^{-\frac{\alpha}{\beta} g(X)}}{D}\right)$ and $\mathrm{D}=\mathrm{kp}^{-\mathrm{e}}$.

$\frac{\partial T P\left(S_{L}, p\right)}{\partial p}=\frac{1}{T}\left[k p^{-e}\left\{\frac{1-e^{-R\left(\frac{1}{\beta} \log (X)+\frac{1}{\alpha} \log (Y)\right)}}{R}+\frac{e^{-R T}\left(1-e^{-\delta\left(T-\frac{1}{\beta} \log (X)-\frac{1}{\alpha} \log (Y)\right)}\right)}{\delta}\right\}-k p^{-e} e\left\{\frac{1-e^{-R\left(\frac{1}{\beta} \log (X)+\frac{1}{\alpha} \log (Y)\right)}}{R}+\frac{e^{-R T}\left(1-e^{-\delta\left(T-\frac{1}{\beta} \log (X)-\frac{1}{\alpha} \log (Y)\right)}\right)}{\delta}\right)\right.$

$+p k p^{-e}\left\{\begin{array}{l}\left(\frac{\left(S_{L}-W\right) e}{k p^{-e} p X}+\frac{-\frac{\alpha^{2} W\left(S_{L}-W\right) e e^{-\frac{\alpha}{\beta} \log (X)}}{k^{2}\left(p^{-e}\right)^{2} p X}+\frac{\alpha W e^{-\frac{\alpha}{\beta} \log (X)}}{k p^{-e} p}}{\alpha Y}\right. \\ e^{-\delta\left(T-\frac{1}{\beta} \log (X)-\frac{1}{\alpha} \log (Y)\right)}\end{array}\right)-e^{-R\left(\frac{1}{\beta} \log (X)+\frac{1}{\alpha} \log (Y)\right)}+e^{-R T}\left(\begin{array}{l}-\frac{\left(S_{L}-W\right) e}{k p^{-e} p X} \\ -\frac{\alpha^{2} W\left(S_{L}-W\right) e e^{-\frac{\alpha}{\beta} \log (X)}}{k^{2}\left(p^{-e}\right)^{2} p X}+\frac{\alpha W e^{-\frac{\alpha}{\beta} \log (X)} e}{k p^{-e} p} \\ \left.-\frac{\alpha Y}{k}\right)\end{array}\right)$

$-\frac{F}{R(R+\beta)}\left\{\frac{-k p^{-e} e\left(e^{-\frac{R}{\beta} \log (X)}-1\right)}{p}-\frac{R\left(S_{L}-W\right) e e^{-\frac{R}{\beta} \log (X)}}{p X}\right\}$ 


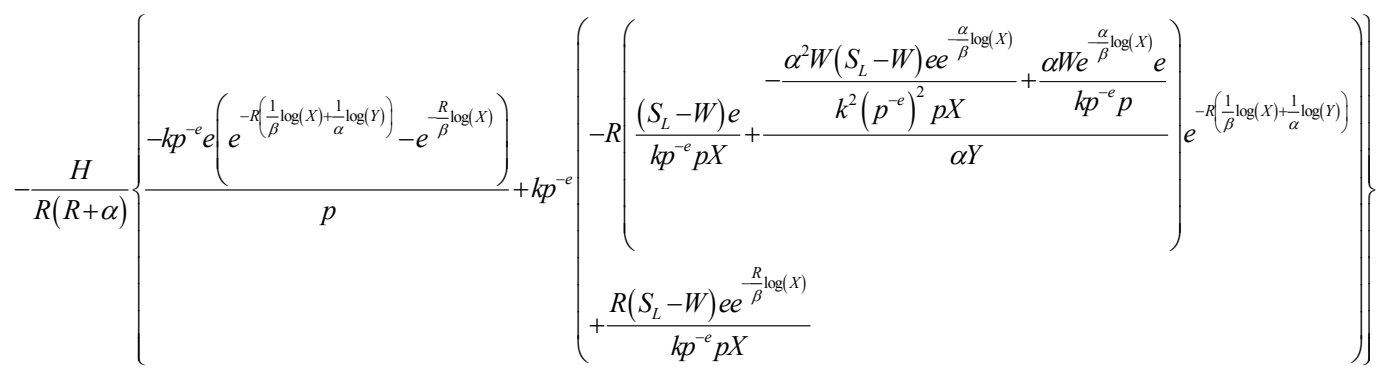

$+\frac{\pi k p^{-e} e}{p \delta}\left\{\frac{e^{-\delta T}\left(e^{(\delta-R) T}-e^{(\delta-R)\left(\frac{1}{\beta} \log (X)+\frac{1}{\alpha} \log (X)\right)}\right)}{(\delta-R)}-\frac{e^{-\delta\left(T-\frac{1}{\beta} \log (X)-\frac{1}{\alpha} \log (Y)\right)}\left(e^{-R\left(\frac{1}{\beta} \log (X)+\frac{1}{\alpha} \log (Y)\right)}-e^{-R T}\right)}{R}\right\}$

$\int-e^{-\delta T}\left(\frac{\left(S_{L}-W\right) e}{k p^{-e} p X}+\frac{-\frac{\alpha^{2} W\left(S_{L}-W\right) e e^{-\frac{\alpha}{\beta} \log (X)}}{k^{2}\left(p^{-e}\right)^{2} p X}+\frac{\alpha W e^{-\frac{\alpha}{\beta} \log (X)} e}{k p^{-e} p}}{\alpha Y}\right) e^{(\delta-R)\left(\frac{1}{\beta} \log (X)+\frac{1}{\alpha} \log (Y)\right)}$

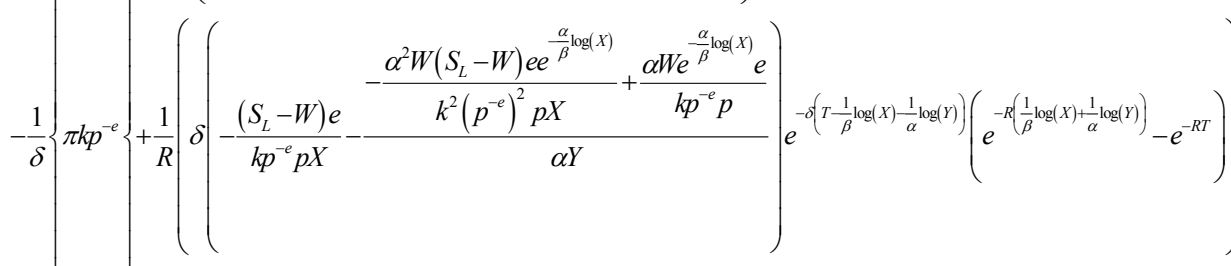

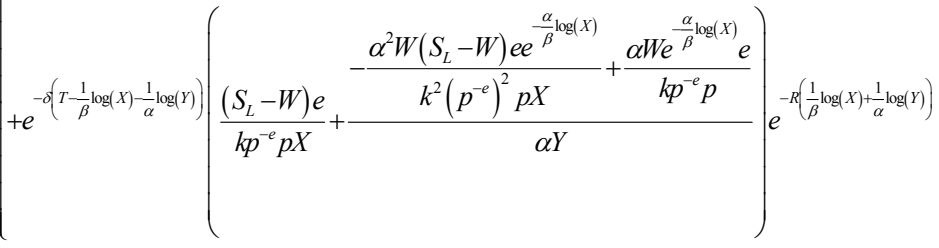

$\frac{\pi_{L} k p^{-e} e e^{-R T}\left(T-\frac{1}{\beta} \log (X)-\frac{1}{\alpha} \log (Y)-\frac{1-e^{-\delta\left(T-\frac{1}{\beta} \log (X)-\frac{1}{\alpha} \log (Y)\right)}}{\delta}\right)}{p}-\pi_{L} k p^{-e} e^{-R T}\left(\begin{array}{l}-\frac{\left(S_{L}-W\right) e}{k p^{-e} p X}- \\ -\frac{\alpha^{2} W\left(S_{L}-W\right) e e^{-\frac{\alpha}{\beta} \log (X)}}{k^{2}\left(p^{-e}\right)^{2} p X}+\frac{\alpha W e^{-\frac{\alpha}{\beta} \log (X)} e}{k p^{-e} p} \\ \alpha Y\end{array}\right)$

$e^{-\delta\left(T-\frac{1}{\beta} \log (X)-\frac{1}{\alpha} \log (Y)\right)}$

$\left.-c\left\{-\frac{k p^{-e} e\left(T-\frac{1}{\beta} \log (X)-\frac{1}{\alpha} \log (Y)\right)}{p}+k p^{-e}\left(-\frac{\left(S_{L}-W\right) e}{k p^{-e} p X}-\frac{-\frac{\alpha^{2} W\left(S_{L}-W\right) e e^{-\frac{\alpha}{\beta} \log (X)}}{k^{2}\left(p^{-e}\right)^{2} p X}+\frac{\alpha W e^{-\frac{\alpha}{\beta} \log (X)} e}{k p^{-e} p}}{\alpha Y}\right)\right]\right\}=0$

where $X=\left(1+\frac{\left(S_{L}-W\right) \beta}{k p^{-e}}\right)$ and $\mathrm{Y}=\left(1+\frac{\alpha W e^{-\frac{\alpha}{\beta} o g(X)}}{k p^{-e}}\right)$

which gives the optimal values of $S_{L}$ and $p$. Further, for the present worth of total average profit, $\operatorname{TP}\left(S_{L}, p\right)$ to be concave, the following sufficient condition must be satisfied.

$$
\frac{\partial^{2} T P\left(S_{L}, p\right)}{\partial S_{L}^{2}} \leq 0, \frac{\partial^{2} T P\left(S_{L}, p\right)}{\partial p^{2}} \leq 0
$$


Since, the second derivative of the present worth of total average profit $T P\left(S_{L}, p\right)$ is complicated and it is very difficult to prove concavity mathematically. Thus, the concavity of the present worth of total average profit has been established graphically (on several data sets) which is shown below. (Fig. 4)

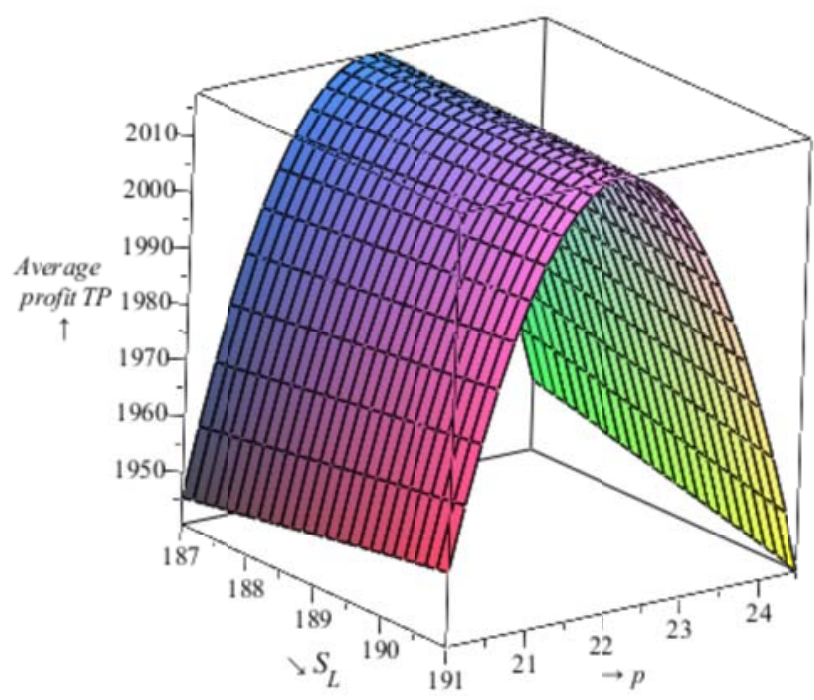

Fig. 4. Average profit versus $S_{L}$ and $p$ for LIFO policy

\section{Numerical Example}

The situation of optimal ordering policies in a two-warehouse system for deteriorating items with pricedependent demand under inflationary conditions and partially backlogged shortages has been presented for two type of dispatching policies: First-In-First-Out (FIFO) or Last-In-First-Out (LIFO).

In this example, we consider an inventory system with the following data:

$k=100000, e=2, A=150, \alpha=0.1, \beta=0.06, W=100, c=10, H=1, F=1, R=0.06, T=1, \delta=$ $0.05, \pi=2, \pi_{L}=4$ in appropriate units.

\section{For FIFO Model,}

$t w=0.47, t_{1}=0.90, p=21.9556, S_{F}=193.33, Q_{F}=213.55$

Total average profit $=2035.64$

\section{For LIFO Model,}

$t w=0.43, t_{1}=0.89, p=22.1346, S_{L}=189.27, Q_{L}=211.66$

Total average profit $=2017.92$

Since the profit in FIFO policy is more than the profit in LIFO policy, so organization should adopt FIFO dispatching policy for the given data set. As the competition in warehouse market is increasing, it is quite likely to rent a warehouse with better preserving facilities at lower costs, than that of OW. Thus, in order to supply their customers with fresh products, organizations prefer to use FIFO dispatch policy instead of LIFO policy. 


\section{Sensitivity Analysis}

In this section, we perform the sensitivity analysis on the key parameters $H, F, R, \delta, k, e, \alpha$ and $\beta$ of the model, in order to study their effect on the policy selection.

I. To study the effect of $H$ and $F$ on the both policies by taking different combinations of $H$ and $F$, when deterioration rate in $\mathrm{OW}$ is greater (i.e. $\alpha=0.1$ and $\beta=0.06$ ). Rest of the parameters are kept same.

\section{Table 1}

Effect of holding cost on the policy selection (When deterioration rate in OW is higher)

\begin{tabular}{ccccccccccc}
\hline $\mathrm{H}$ & $\mathrm{F}$ & $\mathrm{P}$ & $\mathrm{S}_{\mathrm{F}}$ & $\mathrm{Q}_{\mathrm{F}}$ & $\mathrm{TP}(\mathrm{FIFO})$ & $\mathrm{P}$ & $\mathrm{S}_{\mathrm{L}}$ & $\mathrm{Q}_{\mathrm{L}}$ & $\mathrm{TP}(\mathrm{LIFO})$ & $\begin{array}{c}\text { Policy } \\
\text { Suggested }\end{array}$ \\
\hline & 1 & 21.9556 & 193.33 & 213.55 & $\mathbf{2 0 3 5 . 6 4}$ & 22.1346 & 189.27 & 211.66 & $\mathbf{2 0 1 7 . 9 2}$ & FIFO \\
1 & 2 & 22.9219 & 167.76 & 195.58 & $\mathbf{1 9 8 3 . 0 1}$ & 22.6767 & 175.54 & 201.40 & $\mathbf{2 0 0 1 . 4 0}$ & LIFO \\
& 4 & 24.8720 & 129.57 & 165.81 & $\mathbf{1 9 2 0 . 5 8}$ & 23.4952 & 157.23 & 187.27 & $\mathbf{1 9 7 8 . 8 1}$ & LIFO \\
& 1 & 21.7452 & 196.90 & 217.66 & $\mathbf{2 0 1 2 . 7 1}$ & 22.3469 & 179.71 & 207.27 & $\mathbf{1 9 5 6 . 6 4}$ & FIFO \\
2 & 2 & 22.6633 & 171.34 & 200.01 & $\mathbf{1 9 5 8 . 1 6}$ & 22.8704 & 167.08 & 197.65 & $\mathbf{1 9 4 3 . 2 7}$ & FIFO \\
& 4 & 24.4736 & 133.34 & 171.16 & $\mathbf{1 8 9 1 . 6 7}$ & 23.6489 & 150.41 & 184.53 & $\mathbf{1 9 2 5 . 2 9}$ & LIFO \\
& 1 & 21.3655 & 203.62 & 225.38 & $\mathbf{1 9 8 6 . 0 6}$ & 22.9224 & 158.44 & 196.23 & $\mathbf{1 8 4 3 . 7 0}$ & FIFO \\
4 & 2 & 22.2050 & 177.97 & 208.25 & $\mathbf{1 9 0 9 . 9 5}$ & 23.3952 & 148.40 & 188.18 & $\mathbf{1 8 3 6 . 2 3}$ & FIFO \\
& 4 & 23.8023 & 140.11 & 180.79 & $\mathbf{1 8 3 6 . 2 5}$ & 24.0668 & 135.56 & 177.57 & $\mathbf{1 8 2 6 . 6 5}$ & FIFO \\
\hline
\end{tabular}

From (Table 1) the following observation are made:

- If the holding cost and the deterioration rate both are greater in OW than that of RW, then organization should adopt the FIFO policy; as it will be helpful for the decision maker to meet the demand from the OW first, in order to manage the high holding costs of OW.

- If the holding cost in RW is higher than that of OW but the deterioration rate in RW is less than that of OW, then the results show that the cost associated with LIFO dispatching policy is less than the FIFO dispatching policy; LIFO policy is preferred.

- Further, if the holding cost in both of the warehouses is equal but the deterioration rate in OW is larger than that of RW, then FIFO policy is recommended. It helps to sustain maximum freshness of the commodities for the consumer and reduce deterioration cost. So this shows that holding cost plays a dominating role in deterioration rate.

II. We study the effect of $H$ and $F$ on the both policies by taking different combinations of $H$ and $F$, when deterioration rate in RW is greater (i.e. $\alpha=0.06$ and $\beta=0.1$ ). Rest of the parameters are kept same.

Table 2

Effect of holding cost on the policy selection (When deterioration rate in RW is higher)

\begin{tabular}{ccccccccccc}
\hline $\mathrm{H}$ & $\mathrm{F}$ & $\mathrm{P}$ & $\mathrm{S}_{\mathrm{F}}$ & $\mathrm{Q}_{\mathrm{F}}$ & $\mathrm{TP}(\mathrm{FIFO})$ & $\mathrm{P}$ & $\mathrm{S}_{\mathrm{L}}$ & $\mathrm{Q}_{\mathrm{L}}$ & $\mathrm{TP}(\mathrm{LIFO})$ & $\begin{array}{c}\text { Policy } \\
\text { Suggested }\end{array}$ \\
\hline & 1 & 22.4844 & 180.98 & 204.68 & $\mathbf{2 0 2 0 . 7 0}$ & 22.2891 & 185.26 & 206.89 & $\mathbf{2 0 3 7 . 6 2}$ & LIFO \\
1 & 2 & 23.4956 & 156.51 & 186.52 & $\mathbf{1 9 7 6 . 1 4}$ & 22.7864 & 172.95 & 197.61 & $\mathbf{2 0 2 2 . 3 4}$ & LIFO \\
& 4 & 25.6772 & 118.74 & 154.87 & $\mathbf{1 9 2 7 . 9 7}$ & 23.5462 & 156.21 & 184.61 & $\mathbf{2 0 0 0 . 9 6}$ & LIFO \\
& 1 & 22.2397 & 184.83 & 209.24 & $\mathbf{1 9 9 6 . 4 3}$ & 22.4896 & 176.17 & 202.85 & $\mathbf{1 9 7 6 . 2 2}$ & FIFO \\
2 & 2 & 23.1892 & 160.44 & 191.52 & $\mathbf{1 9 4 9 . 7 6}$ & 22.9645 & 164.90 & 194.19 & $\mathbf{1 9 6 3 . 8 4}$ & LIFO \\
& 4 & 25.1671 & 123.20 & 161.28 & $\mathbf{1 8 9 6 . 8 8}$ & 23.6848 & 149.69 & 182.17 & $\mathbf{1 9 4 6 . 7 4}$ & LIFO \\
& 1 & 21.8050 & 191.98 & 217.71 & $\mathbf{1 9 4 9 . 3 2}$ & 23.0169 & 156.21 & 192.82 & $\mathbf{1 8 6 2 . 9 4}$ & FIFO \\
4 & 2 & 22.6574 & 167.62 & 200.67 & $\mathbf{1 8 9 8 . 8 5}$ & 23.4428 & 147.32 & 185.66 & $\mathbf{1 8 5 5 . 9 3}$ & FIFO \\
& 4 & 24.3467 & 130.90 & 172.43 & $\mathbf{1 8 3 7 . 8 4}$ & 24.0607 & 135.62 & 175.97 & $\mathbf{1 8 4 6 . 5 9}$ & LIFO \\
\hline
\end{tabular}


As per observation from (Table 2):

- LIFO policy is used if both the holding cost and deterioration rate in RW is high. It saves the organization from acquiring high holding costs for a longer period. So RW is vacated first i.e., items in RW are sold out first.

- FIFO policy is adopted by the organization if holding cost in RW is comparative less than that of OW, even though the deterioration rate in OW is less than that of RW. This clearly suggests that holding cost plays a significant role in optimal decision making than deterioration rate.

- However, if the holding cost in both the warehouses is same but deterioration rate in RW is high, then LIFO policy is recommended. As the items stored in RW are more prone to deterioration, therefore the RW is to be given priority over OW, so as to administer the loss due to deterioration.

III. Further, Table 3 summarises the finding for different rates of deterioration along with holding costs in both the warehouses in such a fashion which serve as a ready reckoner for the decision maker to arrive at appropriate policy decision.

Table 3

Effect of holding cost and deterioration rate on the policy selection

\begin{tabular}{|c|c|c|c|c|c|c|c|c|c|c|}
\hline \multirow[b]{2}{*}{ RW } & \multirow{2}{*}{$\frac{\mathrm{OW}}{\beta}$} & \multicolumn{2}{|c|}{$\mathrm{H}=1$} & \multirow[b]{2}{*}{$\alpha=0.20$} & \multicolumn{3}{|c|}{$\mathrm{H}=2$} & \multicolumn{3}{|c|}{$\mathrm{H}=3$} \\
\hline & & $\alpha=0.10$ & $\alpha=0.15$ & & $\alpha=0.10$ & $\alpha=0.15$ & $\alpha=0.20$ & $\alpha=0.10$ & $\alpha=0.15$ & $\alpha=0.20$ \\
\hline \multirow{3}{*}{$\mathrm{F}=1$} & 0.10 & EITHER & FIFO & FIFO & FIFO & FIFO & FIFO & FIFO & FIFO & FIFO \\
\hline & 0.15 & LIFO & EITHER & FIFO & FIFO & FIFO & FIFO & FIFO & FIFO & FIFO \\
\hline & 0.20 & LIFO & LIFO & EITHER & LIFO & FIFO & FIFO & FIFO & FIFO & FIFO \\
\hline \multirow{3}{*}{$F=2$} & 0.10 & LIFO & LIFO & FIFO & EITHER & FIFO & FIFO & FIFO & FIFO & FIFO \\
\hline & 0.15 & LIFO & LIFO & LIFO & LIFO & EITHER & FIFO & FIFO & FIFO & FIFO \\
\hline & 0.20 & LIFO & LIFO & LIFO & LIFO & LIFO & EITHER & LIFO & FIFO & FIFO \\
\hline \multirow{3}{*}{$\mathrm{F}=3$} & 0.10 & LIFO & LIFO & LIFO & LIFO & LIFO & FIFO & EITHER & FIFO & FIFO \\
\hline & 0.15 & LIFO & LIFO & LIFO & LIFO & LIFO & LIFO & LIFO & EITHER & FIFO \\
\hline & 0.20 & LIFO & LIFO & LIFO & LIFO & LIFO & LIFO & LIFO & LIFO & EITHER \\
\hline
\end{tabular}

IV. Now we study the impact of $R$ (inflation) on both policy selections, when the deterioration rates ( $\alpha$ and $\beta$ ) are in different combinations and rest of the parameters are to be kept same.

Table 4

Effect of inflation and deterioration on the policy selection

\begin{tabular}{|c|c|c|c|c|c|c|c|c|c|}
\hline $\mathrm{R}$ & $\mathrm{P}$ & $\mathrm{S}_{\mathrm{F}}$ & $\mathrm{Q}_{\mathrm{F}}$ & TP(FIFO) & $\mathrm{P}$ & $\mathrm{S}_{\mathrm{L}}$ & $\mathrm{Q}_{\mathrm{L}}$ & TP(LIFO) & $\begin{array}{c}\text { Policy } \\
\text { Suggested }\end{array}$ \\
\hline \multicolumn{10}{|c|}{ When $\alpha=\beta=0.06$} \\
\hline 0.02 & 21.6207 & 197.57 & 219.20 & 2133.69 & 21.6207 & 197.57 & 219.20 & 2133.69 & \\
\hline 0.06 & 22.0506 & 190.79 & 210.78 & 2045.25 & 22.0506 & 190.79 & 210.78 & 2045.25 & \\
\hline 0.08 & 22.2674 & 187.48 & 206.71 & 2002.56 & 22.7674 & 187.48 & 206.71 & 2002.56 & \\
\hline \multicolumn{10}{|c|}{ When $\alpha>\beta$ (i.e., $\alpha=0.1, \beta=0.06$ ) } \\
\hline 0.02 & 21.5345 & 200.00 & 221.86 & 2124.44 & 21.6962 & 196.06 & 220.17 & 2106.15 & \\
\hline 0.04 & 21.7445 & 196.64 & 217.66 & 2079.52 & 21.9147 & 192.64 & 215.86 & 2061.51 & FIFO \\
\hline 0.06 & 21.9556 & 193.33 & 213.55 & 2035.64 & 22.1346 & 189.27 & 211.66 & 2017.92 & \\
\hline 0.08 & 22.1677 & 190.07 & 209.54 & 1992.76 & 22.3561 & 185.95 & 207.54 & 1975.35 & \\
\hline \multicolumn{10}{|c|}{ When $\alpha<\beta$ (i.e., $\alpha=0.06, \beta=0.1$ ) } \\
\hline 0.02 & 22.0340 & 187.51 & 213.13 & 2107.68 & 21.8582 & 191.66 & 215.12 & 2125.21 & \\
\hline 0.04 & 22.2584 & 184.22 & 208.86 & 2063.67 & 22.0731 & 188.44 & 210.95 & 2080.90 & LIFO \\
\hline 0.06 & 22.4844 & 180.98 & 204.68 & 2020.70 & 22.2891 & 185.26 & 206.89 & 2037.62 & \\
\hline 0.08 & 22.7118 & 177.79 & 200.60 & 1978.74 & 22.5061 & 182.13 & 202.92 & 1995.34 & \\
\hline
\end{tabular}

Table 4 suggests that:

- When inflation rate is increasing, then the present worth of total average profit decreases. It is apparent from the table that order quantity is more when the inflation is low, and it gradually declines with growing inflation. Since with mounting inflation, the prices are ought to rise, 
which results in stumpy demand. Thus in order to sustain expanding inflation rates the organization orders less, which also results in low profits.

- From the table it is clearly visible that again deterioration rate plays a vital role in policy selection, rather than the inflation rate. When the holding cost are same in both the warehouse then the following observations are made with respect to the deterioration rate:

$>$ When the deterioration rate in $\mathrm{OW}$ is equal to that of $\mathrm{RW}$, present worth of total average profit in both the policies is equal. Hence, the organization can adopt either LIFO or FIFO dispatching policy.

$>$ When the deterioration rate in OW is less than that of RW, present worth of total average profit in FIFO system is smaller than LIFO system. As the units in RW deteriorate rapidly, thus it is advisable to consume the goods of RW prior to that of OW.

$>$ On the other hand, if the deterioration rate in OW is more than that of RW, then present worth of total average profit in FIFO system is higher than that of LIFO system. Since in this case the items in RW are deteriorating at a slower rate, so operating OW prior to the $\mathrm{RW}$ is beneficial. Therefore FIFO policy is suggested which helps one to preserve the freshness of the commodities for the consumer.

V. Here the impact of backlogging parameter $\delta$ is considered on the policy selection. Sensitivity analysis is performed by changing (increasing or decreasing) the backlogging parameter $\delta$ by $20 \%$ and $40 \%$. All other parameters are remains same.

\section{Table 5}

Effect of backlogging rate on the policy selection

\begin{tabular}{cccccccccc}
\hline$\delta$ & $\mathrm{P}$ & $\mathrm{S}_{\mathrm{F}}$ & $\mathrm{Q}_{\mathrm{F}}$ & $\mathrm{TP}(\mathrm{FIFO})$ & $\mathrm{P}$ & $\mathrm{S}_{\mathrm{L}}$ & $\mathrm{Q}_{\mathrm{L}}$ & $\mathrm{TP}(\mathrm{LIFO})$ & $\begin{array}{c}\text { Policy } \\
\text { Suggested }\end{array}$ \\
\hline 0.7 & 22.0009 & 197.28 & 212.93 & $\mathbf{2 0 3 2 . 0 4}$ & 22.1834 & 193.77 & 211.11 & $\mathbf{2 0 1 3 . 4 3}$ & FIFO \\
0.6 & 21.9809 & 195.55 & 213.20 & $\mathbf{2 0 3 3 . 6 1}$ & 22.1619 & 191.81 & 211.35 & $\mathbf{2 0 1 5 . 3 9}$ & FIFO \\
0.4 & 21.9224 & 190.33 & 214.00 & $\mathbf{2 0 3 8 . 3 5}$ & 22.0992 & 185.86 & 212.05 & $\mathbf{2 0 2 1 . 3 1}$ & FIFO \\
0.3 & 21.8773 & 186.09 & 214.62 & $\mathbf{2 0 4 2 . 1 6}$ & 22.0511 & 181.03 & 212.59 & $\mathbf{2 0 2 6 . 0 7}$ & FIFO \\
\hline
\end{tabular}

- (Table 5) indicates that a decrease in backlogging parameter $\delta$, i.e., an increase in backlogging rate, increases the order quantity which eventually results in higher profits. Since an increasing backlogging rate implies more of backlogged demand, hence from the order size, a major portion is utilized for satisfying the backlogged demand, which reduces the initial inventory for the organization and thus the inventory holding costs. Further as the deterioration rate is higher in OW, the FIFO dispatch policy is suggested.

VI. Now again we study the effect of $k$ and $e$ on both of the policies by taking different combinations of $k$ and $e$ and keeping all other parameters same as in case of base numerical.

\section{Table 6}

Effect of different values of demand parameters on the both policies

\begin{tabular}{|c|c|c|c|c|c|c|c|c|c|c|}
\hline $\mathrm{K}$ & $\mathrm{E}$ & $\mathrm{P}$ & $\mathrm{S}_{\mathrm{F}}$ & $\mathrm{Q}_{\mathrm{F}}$ & TP(FIFO) & $\mathrm{P}$ & $\mathrm{S}_{\mathrm{L}}$ & $\mathrm{Q}_{\mathrm{L}}$ & TP(LIFO) & $\begin{array}{c}\text { Policy } \\
\text { suggested }\end{array}$ \\
\hline \multirow[t]{3}{*}{100000} & 1.8 & 24.7696 & 290.47 & 318.18 & 3964.74 & 24.8547 & 288.58 & 318.43 & 3940.25 & \multirow{3}{*}{ FIFO } \\
\hline & 2 & 21.9556 & 193.33 & 213.55 & 2035.64 & 22.1346 & 189.27 & 211.66 & 2017.92 & \\
\hline & 2.2 & 20.0094 & 127.69 & 141.95 & 1028.77 & 20.4083 & 120.23 & 136.47 & 1021.62 & \\
\hline \multirow[t]{3}{*}{200000} & 1.8 & 24.8056 & 578.54 & 633.76 & 8089.14 & 24.8240 & 578.25 & 635.73 & 8058.22 & \multirow{3}{*}{ FIFO } \\
\hline & 2 & 22.0264 & 382.88 & 422.97 & 4235.66 & 22.0675 & 381.38 & 423.86 & 4208.30 & \\
\hline & 2.2 & 20.1555 & 249.44 & 277.35 & 2229.31 & 20.2502 & 246.15 & 276.45 & 2207.35 & \\
\hline \multirow[t]{3}{*}{300000} & 1.8 & 24.8124 & 867.14 & 949.91 & 12211.40 & 24.8193 & 867.38 & 952.46 & 12178.34 & \multirow{3}{*}{ FIFO } \\
\hline & 2 & 22.0398 & 573.25 & 633.29 & 6432.53 & 22.0565 & 572.61 & 635.11 & 6401.95 & \\
\hline & 2.2 & 20.1839 & 372.44 & 414.15 & 3425.10 & 20.2239 & 370.54 & 414.76 & 3398.21 & \\
\hline
\end{tabular}

Table 6 shows that: 
- For a fixed value of $e$ (demand parameter), when the demand parameter $k$ increases, then there is a sheer increase in the order quantity and hence the profit also increases. Obviously, as the demand parameter $k$ is directly proportional to the demand, the rise in $k$ escalates the demand, which forces the organization to order a large quantity.

- Whereas, for a fixed value of $k$, an increase in demand parameter $e$ would result in a lesser order quantity. Since $e$ has an inverse effect on the demand, thus the order size decreases which eventually decreases the profit.

The sensitivity analysis section helps the firm to identify and distinguish the parameters which influence the policy selection, and the parameters which influence the policy decision. It is evident from the tables 1, 2 and 3 that holding costs and deterioration rates in both the warehouses playa a major role in selecting the appropriate dispatching policy i.e., FIFO or LIFO. Whereas, the other parameters viz., inflation rate, backlogging rate and the demand parameters, do not play a role in policy selection. However these parameters suggest the firm to take appropriate policy decision i.e., the order quantity and the price for the product which may yield maximum profit in a particular case.

\section{Conclusion}

This paper has investigated the effect of FIFO and LIFO dispatching policies for deteriorating items in a two warehouse inventory system with price-sensitive demand under inflationary conditions. In addition, shortages are partially backlogged. The backlogging rate is considered to be an exponential decreasing function of the waiting time, since the willingness for a customer to wait for backlogging during a shortage period diminishes with the length of the waiting time. The developed models for both FIFO and LIFO dispatching policy jointly optimise the selling price and the initial inventory by maximizing the average profit.

The findings have been validated with the help of a numerical example. Moreover sensitivity analysis reveals the different parameters which influence the dispatching policy selection and policy decision. The policy selection i.e., FIFO or LIFO is only affected by the holding costs and the deterioration rates. However, the inflation rate, backlogging rate and the demand parameters, helps the decision maker to adopt appropriate inventory and pricing policy.

In future the model can be extended by incorporating some more practical situations, stock dependent demand, linear time dependent demand, trade credit policies and many more.

\section{Acknowledgment}

The first and third author would like to acknowledge the financial support provided by University Grants Commission through University of Delhi to accomplish this research. (Vide Research Grant No. DRCH/R\&D/2013-14/4155)

\section{References}

Abad, P. L. (1996). Optimal pricing and lot-sizing under conditions of perishability and partial backordering. Management Science, 42(8), 1093-1104.

Aggarwal, S. P., \& Jaggi, C. K. (1989). Ordering policy for decaying inventory.International Journal of Systems Science, 20(1), 151-155.

Bierman, H., \& Thomas, J. (1977). Inventory decisions under inflationary conditions. Decision Sciences, 8(1), 151-155.

Buzacott, J. A. (1975). Economic order quantities with inflation. Operational research quarterly, 553558.

Cohen, M. A. (1977). Joint pricing and ordering policy for exponentially decaying inventory with known demand. Naval Research Logistics Quarterly, 24(2), 257-268. 
Dey, J. K., Mondal, S. K., \& Maiti, M. (2008). Two storage inventory problem with dynamic demand and interval valued lead-time over finite time horizon under inflation and time-value of money. European Journal of Operational Research, 185(1), 170-194.

Dye, C. Y., Ouyang, L. Y., \& Hsieh, T. P. (2007). Deterministic inventory model for deteriorating items with capacity constraint and time-proportional backlogging rate. European Journal of Operational Research, 178(3), 789-807.

Hartley, R. V. (1976). Operations research: a managerial emphasis (Vol. 976). Goodyear.

Hsieh, T. P., Dye, C. Y., \& Ouyang, L. Y. (2008). Determining optimal lot size for a two-warehouse system with deterioration and shortages using net present value. European Journal of Operational Research, 191(1), 182-192.

Jaggi, C. K., \& Verma, P. (2008). Joint optimization of price and order quantity with shortages for a two-warehouse system. Top, 16(1), 195-213.

Jaggi, C. K., Aggarwal, K. K., \& Goel, S. K. (2006). Optimal order policy for deteriorating items with inflation induced demand. International Journal of Production Economics, 103(2), 707-714.

Jaggi, C. K., Aggarwal, K. K., \& Verma, P. (2010). Inventory and pricing strategies for deteriorating items with limited capacity and time-proportional backlogging rate. International Journal of Operational Research, 8(3), 331-354.

Jaggi, C. K., Khanna, A., \& Verma, P. (2011). Two-warehouse partial backlogging inventory model for deteriorating items with linear trend in demand under inflationary conditions. International Journal of Systems Science, 42(7), 1185-1196.

Jaggi, C. K., Khanna, A., Pareek, S., \& Sharma, R. (2013). Ordering Policy in a Two-Warehouse Environment for Deteriorating Items with Shortages under Inflationary Conditions. International Journal of Strategic Decision Sciences (IJSDS), 4(2), 27-47.

Jaggi, C. K., Pareek, S., Verma, P., \& Sharma, R. (2013). Ordering policy for deteriorating items in a two-warehouse environment with partial backlogging.International Journal of Logistics Systems and Management, 16(1), 16-40.

Jaggi, C. K., Pareek, S., Khanna, A., \& Sharma, R. (2014). Credit financing in a two-warehouse environment for deteriorating items with price-sensitive demand and fully backlogged shortages. Applied Mathematical Modelling.

Jaggi, C. K., \& Verma, P. (2010). A deterministic order level inventory model for deteriorating items with two storage facilities under FIFO dispatching policy. International Journal of Procurement Management, 3(3), 265-278.

Lee, C. C. (2006). Two-warehouse inventory model with deterioration under FIFO dispatching policy. European Journal of Operational Research, 174(2), 861-873.

Lee, C. C., \& Hsu, S. L. (2009). A two-warehouse production model for deteriorating inventory items with time-dependent demands. European Journal of Operational Research, 194(3), 700-710.

Mukhopadhyay, S., Mukherjee, R. N., \& Chaudhuri, K. S. (2004). Joint pricing and ordering policy for a deteriorating inventory. Computers \& Industrial Engineering, 47(4), 339-349.

Mukhopadhyay, S., Mukherjee, R. N., \& Chaudhuri*, K. S. (2005). An EOQ model with twoparameter Weibull distribution deterioration and price-dependent demand. International Journal of Mathematical Education in Science and Technology, 36(1), 25-33.

Niu, B., \& Xie, J. (2008). A note on "Two-warehouse inventory model with deterioration under FIFO dispatch policy". European Journal of Operational Research, 190(2), 571-577.

Rong, M., Mahapatra, N. K., \& Maiti, M. (2008). A two warehouse inventory model for a deteriorating item with partially/fully backlogged shortage and fuzzy lead time. European Journal of Operational Research, 189(1), 59-75.

Sarma, K. V. S. (1983). A deterministic inventory model with two levels of storage and an optimum release rule. Opsearch, 20(3), 175-180.

Shah, N. H., \& Shukla, K. T. (2009). Deteriorating inventory model for waiting time partial backlogging. Applied Mathematical Sciences, 3(9), 421-428.

Wee, H. M. (1997). A replenishment policy for items with a price-dependent demand and a varying rate of deterioration. Production Planning \& Control, 8(5), 494-499. 
Wee, H. M. (1999). Deteriorating inventory model with quantity discount, pricing and partial backordering. International Journal of Production Economics, 59(1), 511-518.

Yang, H. L. (2004). Two-warehouse inventory models for deteriorating items with shortages under inflation. European Journal of Operational Research, 157(2), 344-356.

Yang, H. L. (2006). Two-warehouse partial backlogging inventory models for deteriorating items under inflation. International Journal of Production Economics, 103(1), 362-370.

Yang, H. L. (2012). Two-warehouse partial backlogging inventory models with three-parameter Weibull distribution deterioration under inflation. International Journal of Production Economics, 138(1), 107-116. 